\title{
Numerical and Experimental Analysis of Stacking Sequences Effects in Composite Mechanical Joints under Impact Loadings
}

\author{
Pourya Fathi, Alireza Naddaf Oskouei, Khodadad Vahedi, Amin Moslemi Petrudi \\ Department of Mechanical Engineering, Tehran University, Iran \\ amin.moslemi2020@gmail.com, http:/ /orcid.org/0000-0002-5928-0479
}

\begin{abstract}
The paper deals with composite structures in the field of advanced and modern structures in engineering design and according to high specification of composite materials such as high strength to weight ratio use in various industries such as aerospace, marine. One of the most important fields that Researchers have paid less attention to that is to investigate the effect of stacking sequence on the strength of mechanical joints under impact loading. In view of changing the mechanical properties of composite materials by changing the arrangement of layers, in this study, the effect of different orientation of layers on the strength of pin joints in glass-epoxy composites under low-velocity tensile impact has been investigated. Using the Abaqus software and the finite element method, the impact simulation and the force applied to the mechanical joint were analyzed. To evaluate the simulations, the results of the finite element method have been compared with the experimental results. By observing the results, the introduced finite element model is well-considered and is well-matched with the result of the experimental dataset, which made it a valuable tool for predicting the strength of multi-layer composite materials under impact loadings. Using the results of the model, one can analyze the distribution and type of stress and strain in each layer of composite.
\end{abstract}

KEYwORDS. Composites; Mechanical Joint; Joints Strength; Stacking Sequence; Tensile Impact.

\section{open Access}

Citation: Fathi, P., Oskouei, A. N., Vahedi, K., Petrudi, A. M., Numerical and Experimental Analysis of Stacking Sequences Effects in Composite Mechanical Joints under Impact Loadings, Frattura ed Integrità Strutturale, 53 (2020) 457-473.

Received: 17.05 .2020

Accepted: 12.06 .2020

Published: 01.07.2020

Copyright: (C) 2020 This is an open access article under the terms of the CC-BY 4.0, which permits unrestricted use, distribution, and reproduction in any medium, provided the original author and source are credited.

\section{INTRODUCTION}

$\mathrm{D}$ ue to the progress of the industry in the field of composites and the fact that composites have significant properties such as high resistance to weight ratio, researchers and experts are exploring various aspects of their application. In the field of mechanical engineering, composites are one of the most important topics, especially in the field of solids. Combining two or more materials together to be chemically separate and insoluble, the composite yield and structural properties of each compound are considered superior to each of its constituents alone. Due to this, Composite and metal alloy are different. Therefore, a composite is a combination of at least two separate materials with a specified cross-section between each constituent [1]. Composites have found wide application in the marine, aerospace, defense, automotive industries due to their advantages and properties. An example of the use of composites in the aerospace industry is shown in Fig. 1 [2]. Much work has been done to model and analyze the impact of low velocity impacts on composites and 
researchers have investigated this issue with different perspectives. One of the tasks done in this regard is to calculate the force of the impact loading steps. These investigations examined the effects of layer thickness and impact velocity on contact force and contact time. In another series of studies, the deformation and fracture of composite materials has been investigated. In 2015, Long et al., Conducted a study on the prediction of delamination in composite multilayers affected by low velocity impacts. In this study, they investigated numerically the Hashin criterion in modeling this issue and ultimately influenced their research through experiments [3]. In 2015 Singh et al. [4] investigated and compared the strength of composite components with pin joint under tensile loading in three lay-up technique $\left[0^{\circ}, 45^{\circ}, 0^{\circ}\right]$ and $\left[0^{\circ}, 90^{\circ}, 0^{\circ}\right]$ as well as $\left[0^{\circ}, 45^{\circ}, 90^{\circ}\right]$ used. They also investigated the effect of the segment-to-diameter ratio of the hole and validated their results with experiments. In 2016 Senthil kumar et al. [5] investigated the effect of fiber angles on the strength of composite components under tensile loading on Sisal-reinforced composite. They examined 6 different patch layers. They performed their experiments and used electron imaging to extract the results. In 2018, Ali Jogi et al. [6] investigated the effect of fiber angles on the strength of composite components with epoxy and Kevlar glass fibers under Izod loading and pendulum impact and validated their results experimentally and finally analyzed the impact of angle changes. B. Kiral [7] investigated effect of the Clearance and Interference-fit on Failure of the Pin-Loaded Composites. The aim of this study is to examine the effect of the clearance and interference-fit on the failure mode, failure load and bearing strength of the pin-loaded joints subjected to traction forces. Mishra et al. [8] investigated failure initiation in composite structures under low-velocity impact and an analytical model for the response of rectangular, especially orthotropic, symmetric laminated composite plates simply supported on all four sides subjected to low-velocity impact at the midpoint of the plate. Kapti et al [9] Experimental and Numerical Failure Analysis of Carbon/Epoxy Laminated Composite. The aim of this study is to investigate the effects of preload moment, moisture and interference-fit on bearing strength and failure mode in pin-jointed and bolted carbonepoxy plates which were subjected to a traction force. Hassan et al [10] investigated low-velocity impact damage of woven fabric composite. The response of Glass Fiber Reinforced Plastic laminates (GFRPs) under low-velocity impact. Experimental tests were performed according to ASTM: D5628 for different initial impact energy levels ranging from $9.8 \mathrm{~J}$ to $29.4 \mathrm{~J}$ and specimen thicknesses of 2,3 and $4 \mathrm{~mm}$. The impact damage process and contact stiffness were studied incrementally until a perforation phase of the layered compounds occurred, in line with a force-deflection diagram and imaging of impacted laminates. Liang et al. [11] Experimental and numerical investigation on bolted joint in glass-fiber reinforced composites. Vacuum assisted resin injection technique was employed to prepare the composite laminates with different plies ways. The macro-mechanical performances of the bolted joint of the composite laminates were investigated by experimental and finite element simulation. Machado et al [12] Numerical study of the behavior of composite mixed adhesive joints. The experimental tests were performed to assess the improvement of quasi-static and impact strength of composite adhesive joints, and with the focus of avoiding early delamination of the composite substrates. Liu et al. [13] investigated the impact damage and residual load capacity of composite stepped bonding repairs and joints. The failure mechanism and responses under low velocity impact are still not expressly revealed. A series of experiments for impact are conducted. Responses of impact contact load, deflection, absorbed energy and speed were tested. A critical impact energy of adhesive damage and residual strength was found. Ondurucu et al. [14] investigated progressive failure analysis of glassepoxy laminated composite pinned-joints. The damage development process of glass-epoxy laminated composite pinnedjoints is investigated. To determine the effects of joint geometry and stacking sequence on the bearing strength and damage mode, experimental studies were carried out. Taghipoor et al [17] Experimental and numerical study on energy absorption of lattice-core sandwich beam. Quasi-static three-point bending tests on sandwich beams with expanded metal sheets as core were conducted. Relationships between the force and displacement at the mid-span of the sandwich beams were obtained from the experiments. Harhash et al. [18] Experimental characterization, analytical and numerical investigations of $\mathrm{metal} / \mathrm{polymer} / \mathrm{metal}$ sandwich composites. the main focus lies on bending conditions, validated by analytical and numerical methods. A wide variety of SPS layer configurations and thicknesses were tested under three-point bending conditions considering different bending angles $\left(60,90\right.$ and $\left.150^{\circ}\right)$ and different punch radii $(1.5,3,6$ and $12 \mathrm{~mm})$. The results are validated in terms of the bending forces, spring back degree, strain field distribution, and thickness reduction. Ruzbahani et al. [19] Experimental Analysis of Composite Sandwich Plates Buckling with Lozenge Core Using the Vibration Correlation Technique. an experimental study of the buckling load of composite sandwich plates with lozenge core has been investigated. The hand lay-up method has been used for fabrication of the composite sandwich plates. One of the specimens was used for the modal test. In order to verify the results of the VCT, the buckling load of four specimens was calculated by the experimental buckling test. The error of VCT was $2.1 \%$. Hence, the efficiency of the VCT for composite sandwich plates with lattice core was confirmed. Li et al. [21] investigated Mechanical and failure properties of rocks with a cavity under coupled static and dynamic loads. The results show that, the dynamic strength of intact specimens and specimens with a cavity decreases with the increase of axial static pressure under $20-70 \%$ of the uniaxial compressive strength (UCS). Cheng et al. [22] investigated interfacial bond behaviour between hybrid carbon/basalt fibre composites and concrete under 
dynamic loading. The hybrid composites have a relatively longer effective bond length under both quasi-static and dynamic loadings. Empirical formulae are proposed based on the test data to predict the dynamic interfacial bonding strength and shear stress between single or hybrid FRP sheet and concrete at various strain rates. Xuan et al. [23] A study on Mg wires/poly-lactic acid composite degradation under dynamic compression and bending load for implant applications. The degradation behaviors of poly-lactic acid (PLA) based composite reinforced with magnesium alloy wires (Mg wires/PLA) under dynamic compression and bending loads are investigated. The results denote the dynamic loads significantly influence the degradation behaviors of the composite. The dynamic bending load would profoundly promote the degradation of $\mathrm{Mg}$ wires in the composite and then accelerate the mechanical properties loss of the composite. In this study, the effect of different orientation of layers on the strength of pin joints in glass-epoxy composites under low-velocity tensile impact has been investigated. Using the Abaqus software and the finite element method, the impact simulation and the force applied to the mechanical joint were analyzed. To evaluate the simulations, the results of the finite element method have been compared with the experimental results. By observing the results, the introduced finite element model is well-considered and is well-matched with the result of the experimental dataset, which made it a valuable tool for predicting the strength of multi-layer composite materials under impact loadings. Using the results of the model, one can analyze the distribution and type of stress and strain in each layer of composite.

\section{CHARPY IMPACT TEST}

$\mathrm{I}$ mpact loading with the types of Charpy impact test, Izod impact test, Tensile impact test, drop weight test have been investigated in various studies. In Tab. 1, Izod Test Details, and in Tab. 2, details of Charpy impact test with three speeds and different standards are given. Tab. 3 shows tensile impact details.

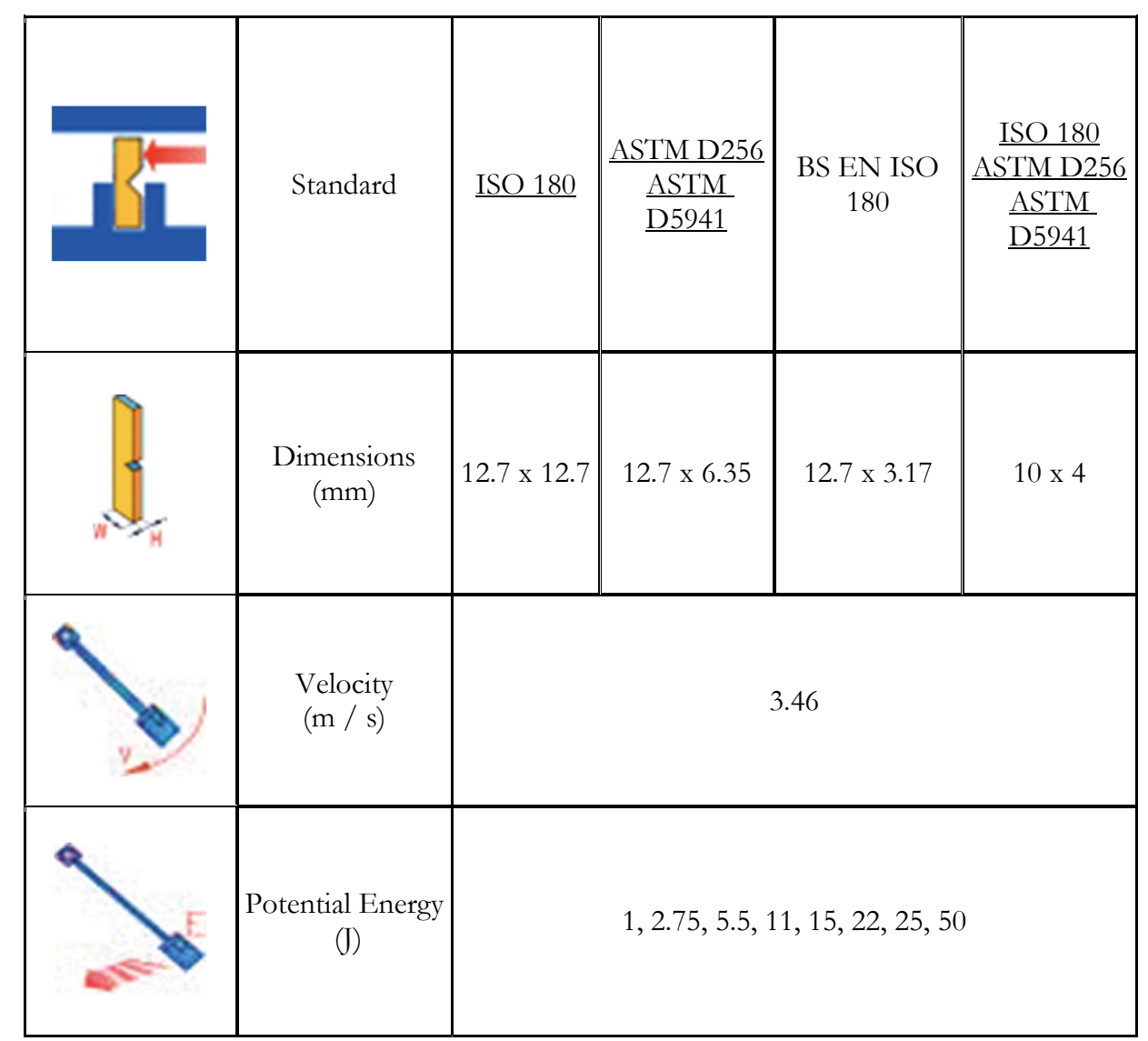

Table 1: Izod Test Details. 


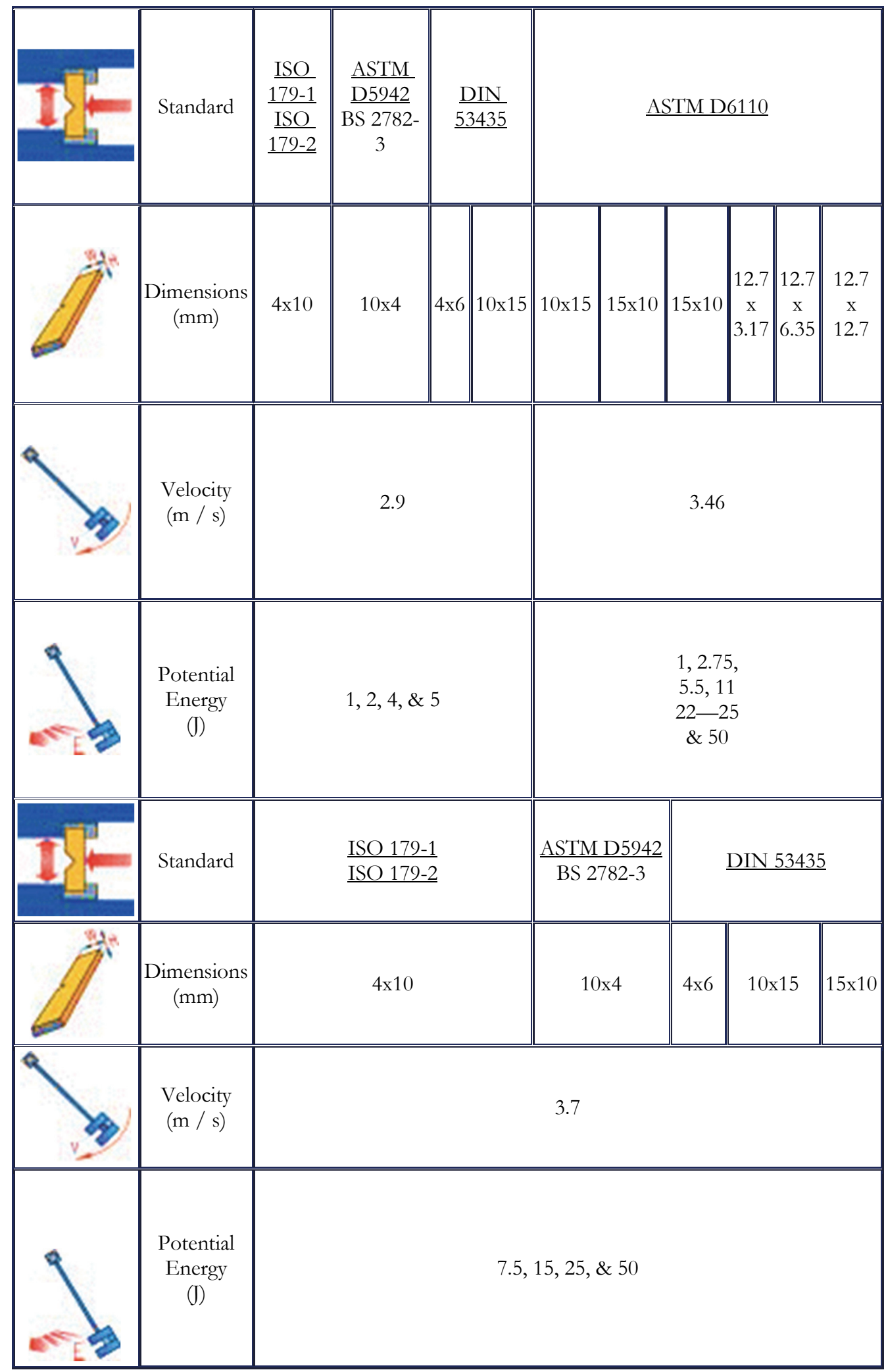

Table 2: Details of Charpy Impact Test with three speeds and different standards. 


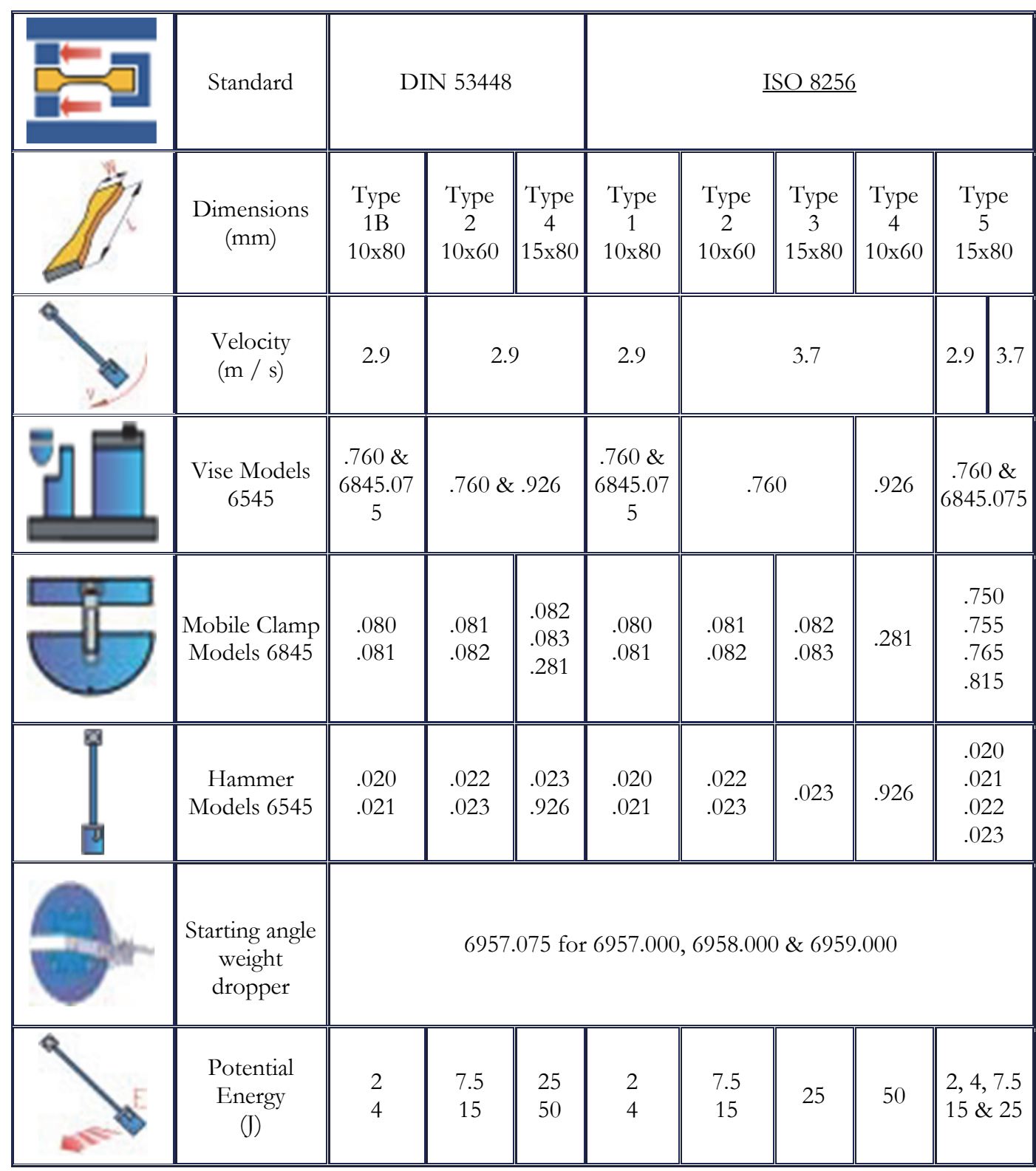

Table 3: Tensile Impact Details.

\section{EXPERIMENTAL STUDY}

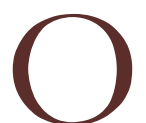

ne of the most important properties is the strength of the composites in mechanical coupling. For this purpose, the method of fabricating and conducting experimental tests on composite specimen with mechanical coupling (PIN) under tensile loading is investigated. First, we will explain how to build a multilayer, and then prepare it for impact traction testing. In this study, a composite and symmetrical plate (length $\mathrm{L}$, width $\mathrm{W}$, thickness $\mathrm{t}$ ) with materials consisting of fiberglass fabrics in $0^{\circ}$ and $90^{\circ}$ directions and epoxy resin were fabricated. The plate is investigated from 8 layers with a layer of $\left[0^{\circ}, 90^{\circ},-45^{\circ}\right.$ and $\left.45^{\circ}\right] \mathrm{s}$ which is symmetric and isotropic with respect to the layer. The geometry of the plate has a hole $d$ in diameter that is located exactly at the centerline of the plate and at a distance from one edge. In this study, five complete specimens were made according to standard dimensions, and the reason is to perform at least five tests according to D1822 standard, which should test at least five fragments in each condition unless valid results can be obtained with fewer tests [15]. After preparation of the specimens, the impact tensile test is performed. Tab. 4 Mechanical properties of composite material is shown. 


\begin{tabular}{|c|c|c|}
\hline Properties & $\begin{array}{l}\text { Glass / Epoxy } \\
\text { (unidirectional) }\end{array}$ & Unit \\
\hline $\begin{array}{l}\text { Longitudinal elastic } \\
\text { modulus }\end{array}$ & $39 \times 10^{6}$ & $\mathrm{E}_{1}\left(\mathrm{~N} / \mathrm{mm}^{2}\right)$ \\
\hline $\begin{array}{c}\text { Transverse elastic } \\
\text { modulus }\end{array}$ & $8 / 6 \times 10^{6}$ & $\mathrm{E}_{2}\left(\mathrm{~N} / \mathrm{mm}^{2}\right)$ \\
\hline Shear modulus & $3 / 8 \times 10^{6}$ & $\mathrm{G}_{12}\left(\mathrm{~N} / \mathrm{mm}^{2}\right)$ \\
\hline $\begin{array}{l}\text { Ultimate longitudinal } \\
\text { tensile strength }\end{array}$ & 1080 & $\mathrm{X}_{\mathrm{t}}(\mathrm{MPa})$ \\
\hline $\begin{array}{l}\text { Ultimate longitudinal } \\
\text { pressure strength }\end{array}$ & 620 & $\mathrm{X}_{\mathrm{c}}(\mathrm{MPa})$ \\
\hline $\begin{array}{l}\text { Ultimate transverse } \\
\text { tensile strength }\end{array}$ & 39 & $\mathrm{Y}_{\mathrm{t}}(\mathrm{MPa})$ \\
\hline $\begin{array}{l}\text { Ultimate transverse } \\
\text { pressure strength }\end{array}$ & 128 & $\mathrm{Y}_{\mathrm{c}}(\mathrm{MPa})$ \\
\hline $\begin{array}{l}\text { Ultimate plate shear } \\
\text { stress }\end{array}$ & 89 & $\mathrm{~S}(\mathrm{MPa})$ \\
\hline $\begin{array}{l}\text { Ultimate shear } \\
\text { strength of the plate }\end{array}$ & 35 & $\mathrm{~S}(\mathrm{MPa})$ \\
\hline Poisson's ratio & 0.28 & $v(-)$ \\
\hline Density & 2100 & $\rho\left(\mathrm{kg} / \mathrm{m}^{3}\right)$ \\
\hline
\end{tabular}

Table 4: Mechanical Joints properties of composite material [16].
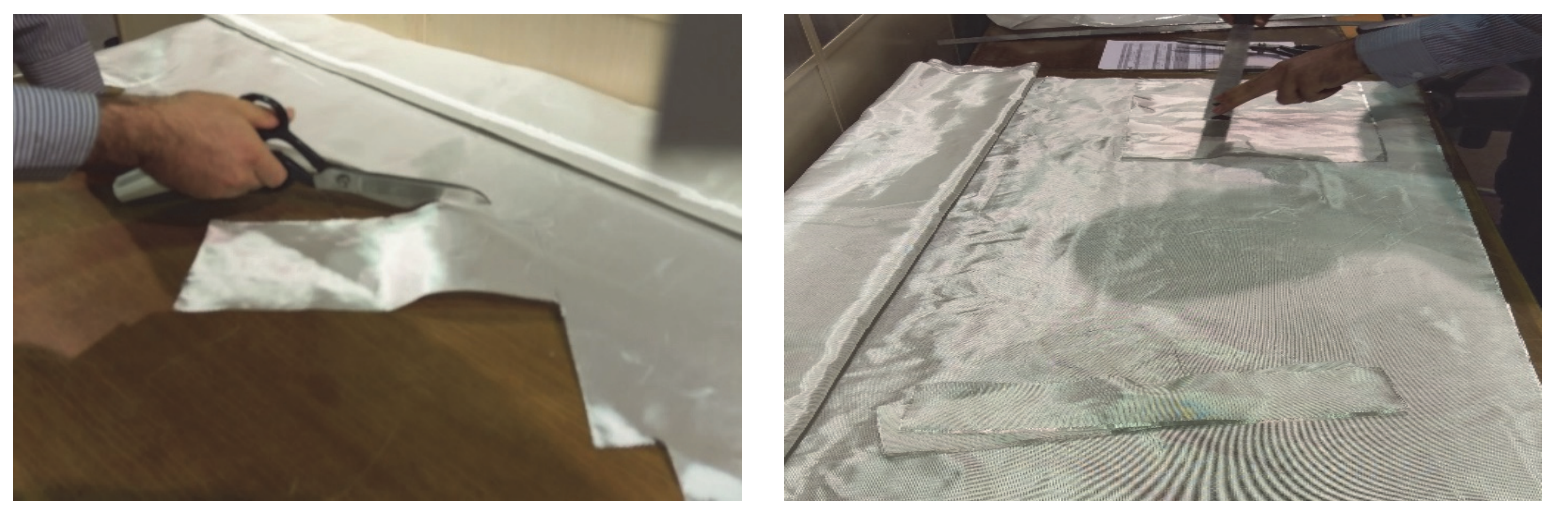

Figure 1: Fabric used in composite plates.
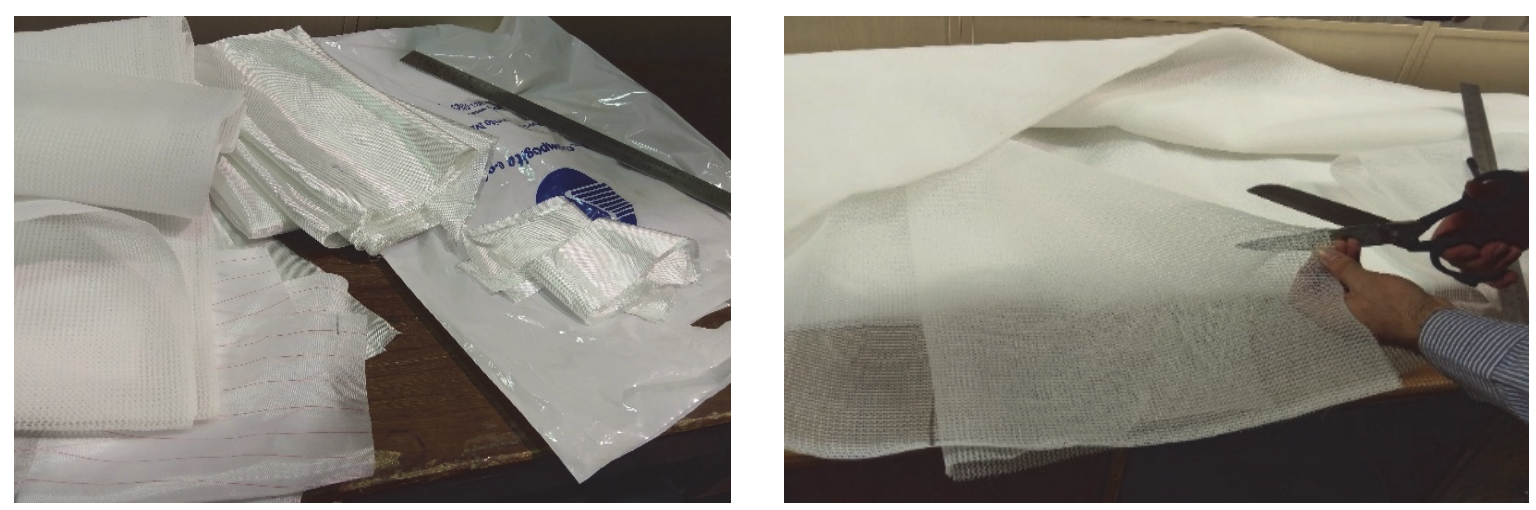

Figure 2: Mesh cut of the fabric and Dacron. 
The resin used in this study is the epoxy resin E.P.L and Hardner H.P.L and the glass fibers used are $0^{\circ}$ and $90^{\circ}$ glass fibers as well as $\left[-45^{\circ}\right.$ and $\left.45^{\circ}\right]$ known as 205 Belarussian. Testing of specimens is performed according to ASTM D1822 and ISO 8256 with impact tensile test. The glass fiber fabric is first selected according to the appropriate test properties and standards and then according to the dimensions and orientation of the layer with predetermined patterns at angles $0^{\circ}$ and $90^{\circ}$ as well as $\left[-45^{\circ}\right.$ and $\left.45^{\circ}\right]$. The fiber line is cut. Dacron fabric and mesh fabric are cut to $10 \mathrm{~cm}$ larger on each side, depending on the size of the original fabric. The laminate composite plate is made of approximately $12 \times 30 \mathrm{~cm}$. Fig. 1 Fabric used in composite plates and Fig. 2 Cut mesh fabric and Dacron is shown.

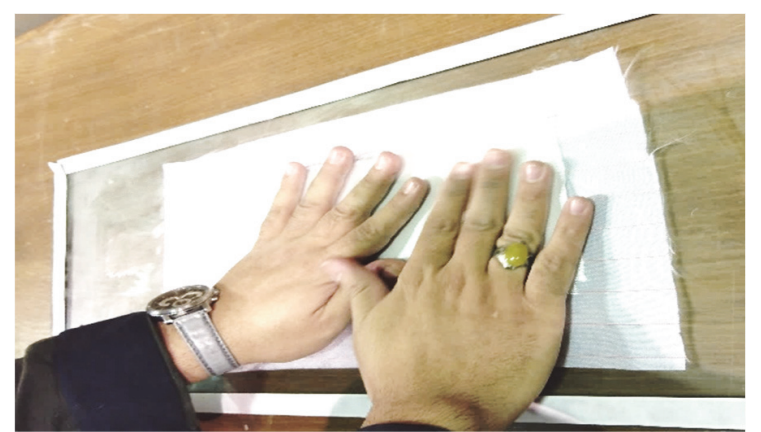

Start the glass fiber layer

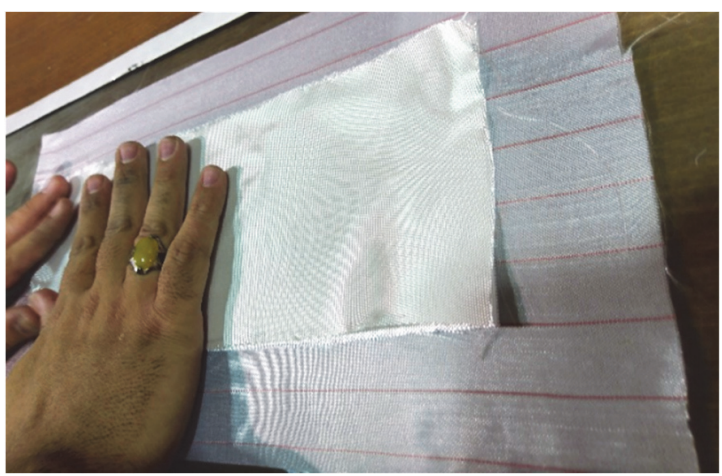

Layering fibers

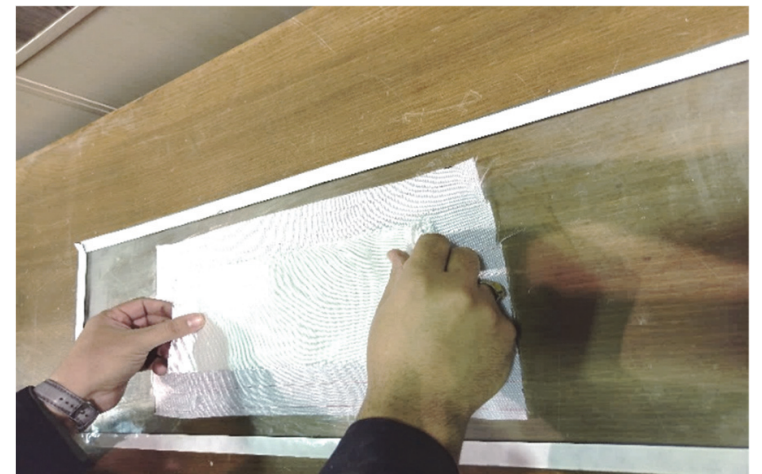

Figure 3: Steps of layering fibers.

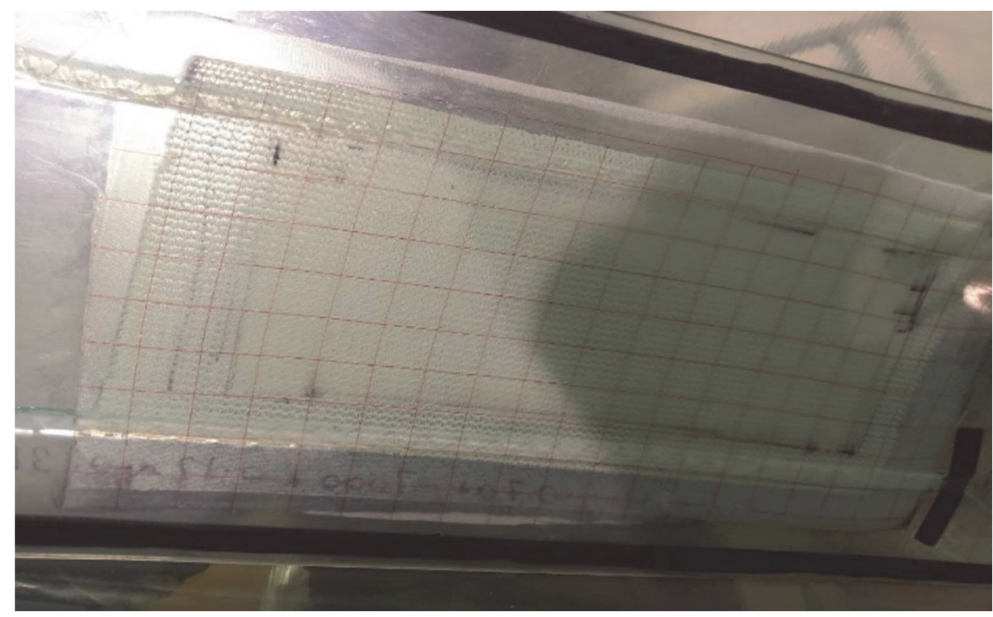

Figure 4: Image after injection.

At this stage the fabric layering begins. First, a layer of Dacron fabric is placed on the glass surface, due to the fact that the piece is not adhered to the glass and creates a smooth, non-polished surface of the specimen, which then does not need to be sandwiched to the pieces for placement in the test apparatus. The next layer is the mesh fabric. The mesh fabric is applied 
to both the substrate and the fiber layer for the highly layered parts, but in this specimen, since the number of layers is 4 , there is no need for two layers of mesh fabric, only the top or bottom. The layer is placed. The next layer is again the Dacron fabric to prevent the mesh fabric from sticking to the piece. At this stage, the segment layer begins: glass fibers $0^{\circ}$ and $90^{\circ}$, glass fibers $\left[-45^{\circ}\right.$ and $45^{\circ}$, glass fibers $\left[-45^{\circ}\right.$ and $45^{\circ}$ ], glass fibers $0^{\circ}$ and $90^{\circ}$, Dacron fabric. Fig. 3 Steps of layering fibers and Fig. 4 Image after injection is shown.

\section{Tensile Impact Test}

Given the research done on this type of loading, very little research has been done on this type of loading and also the research found in this area has often been simulated. After cutting and drilling operations, the specimens were bonded to each other by a rigid pin and sent to Dana Plastics Testing Laboratory to ensure impact tensile testing. Fig. 5 Schematic of specimen's placement and tensile impacts is shown.

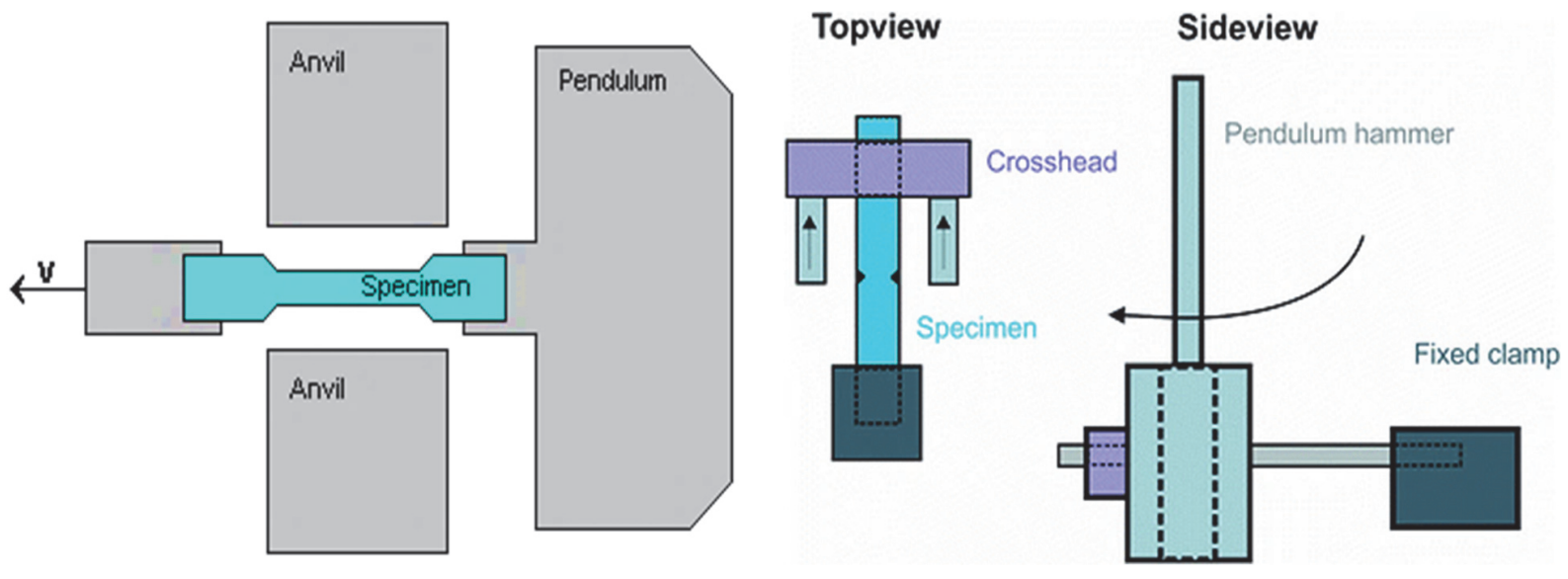

Figure 5: Schematic of specimens placement and impact tensile.

Limitations of the device are specimen placement with a maximum dimension of $25 \times 80 \mathrm{~mm}$ and a maximum thickness of $3 \mathrm{~mm}$. The maximum energy applied to the specimen is $25 \mathrm{~J}$ and the fracture energy above this level cannot be checked. The minimum number of tests tested is 5 tests for the accuracy of the data obtained. According to this standard 5 specimen were prepared and tested on these specimens. Fig. 6 Specimens before the test and Fig. 7 Failed specimen after testing is shown.
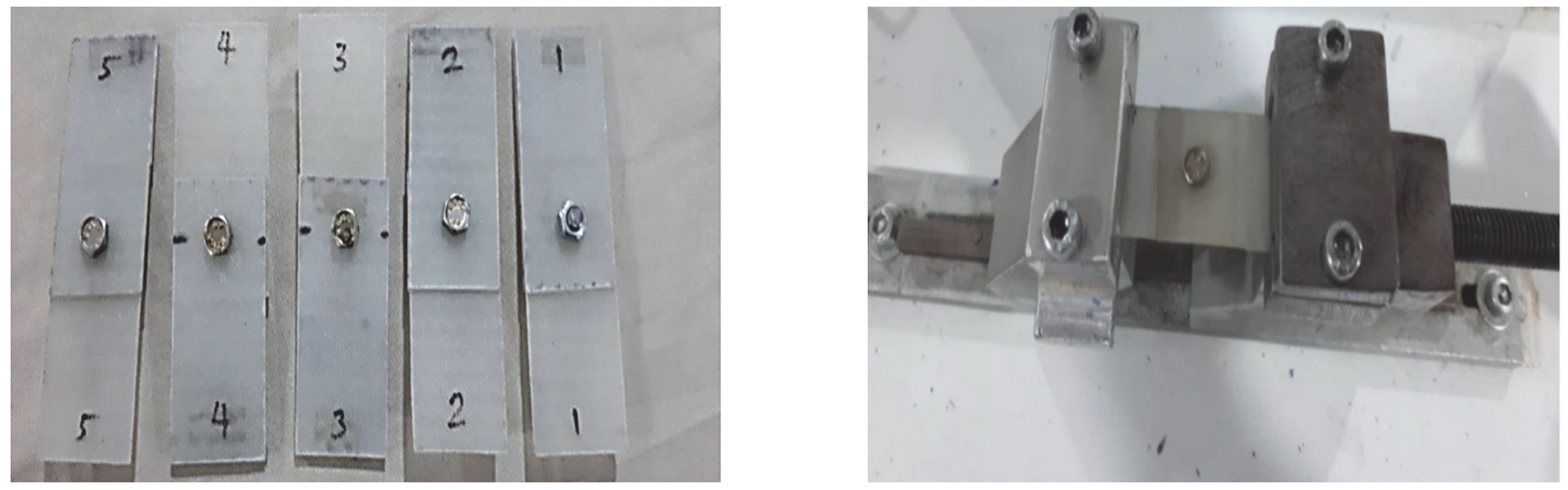

Figure 6: Specimens before the test.

After testing and failing the specimens, the tester provides the fracture energy test number. The test results for layer $\mathrm{s}$ $\left[45^{\circ},-45^{\circ}, 0^{\circ}, 90^{\circ}\right]$ are presented in Tab. 5 . The results of the impact tensile test on composite plates are as follows: The number of specimens and the impact tensile tests should be at least 5 according to the standard. Fig. 8 shows Failed specimens and the specimens prepared for the experimental test. The location of the specimen in the impact tensile test machine is as follows: 
1. The specimen is placed on the fixed and lower jaw of the machine and the pendulum hits the larger jaw and the impact tensile is applied to the specimen.

2. The specimen that is closed on the pendulum and with the lower jaw pendulum of the larger supporter holding the specimen, hits the bottom of the machine and the impact tensile on the specimen.

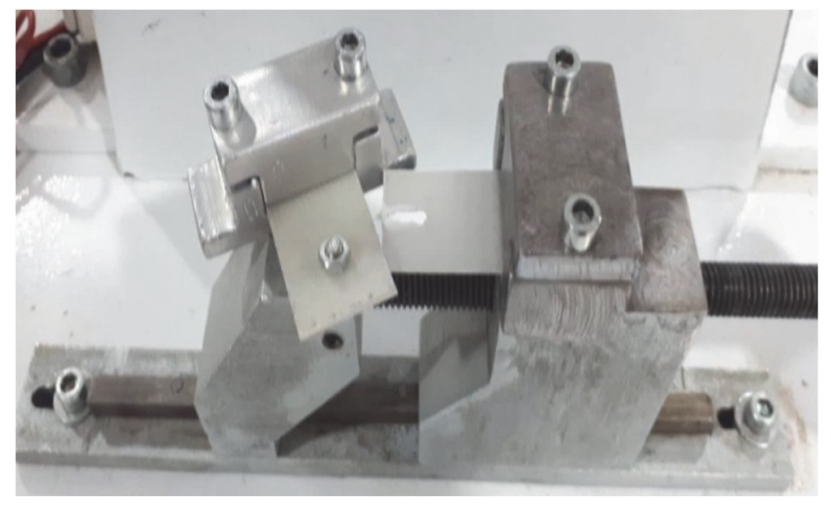

Figure 7: Failed specimen after testing.

\begin{tabular}{ccc}
\hline Measurement index & Standard number & Test result \\
& 561 \\
$\begin{array}{c}\text { Fracture energy of against tensile } \\
\text { strength }(\mathrm{kJ} / \mathrm{m} 2)\end{array}$ & 427 \\
& ISIRI 10919 & 523 \\
& 558 \\
The ultimate strength response against tensile impact failure & 561 \\
\hline
\end{tabular}

Table 5: Impact tensile test results.
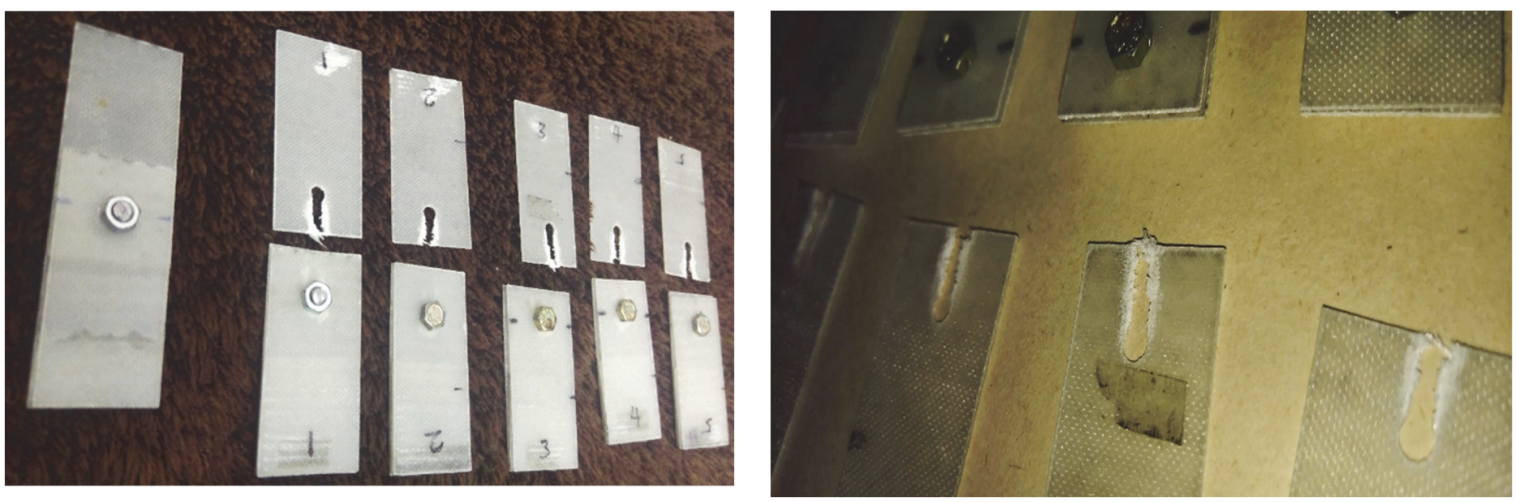

Figure 8: Failed specimen.

\section{Numerical Calculations}

I

$\mathrm{n}$ the design of the model, an attempt has been made to model the failure or rupture of the crush, and this can be seen in the failure patterns of the specimens at the software output. Critical points that begin to fail are connected around the pin hole or visible from the sides and inclined to the back of the pin. In these materials, each layer is supporting a certain amount of stress. If it exceeds the unit value, it means that the layer will fail, but the multilayer may still be able to 
support the load. In the following figures, the places that have been painted red will be damaged and failure will start from these points. To ensure this problem is solved, the model in ABAQUS is two-dimensional with shell element and also with solid element, which is a type of volumetric elements. One of the most important steps in modeling mesh is the desired model. Fig. 9 shows the model of the mesh.
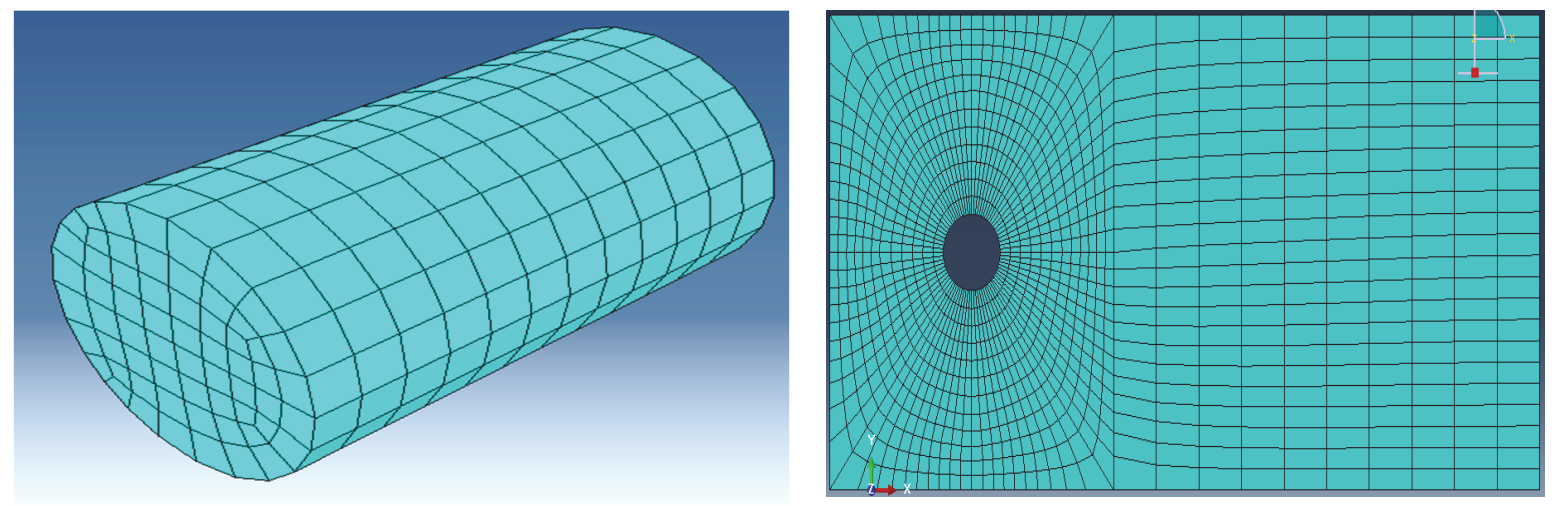

Figure 9: Composite plate mesh with rigid pin and shell element.

Due to the fact that there is a stress concentration around the hole and the stress analysis in this area is desired, so the mesh in this area is considered smaller than other areas. The desired mesh pin is also selected at the point of contact with the surface of the smaller plate to create the necessary matching of the elements at the point of contact. Fig.10 shows Specimen and jaw simulation in ABAQUS software.

According to the tensile impact D1822 standard, the impact velocity of the impact pendulum is constant at the moment of collusion at $2.9 \mathrm{~m} / \mathrm{s}$, and according to the standard tables, the force applied at the moment of collusion is constant and can be calculated according to the impact and energy relations.

There have been many changes in the model to achieve structural configuration until the software easily meshes and solves the model and gives the correct response and convergence. The number of 20 node elements in each model line, the difference in responses was less than $1 \%$ and the number 25 was selected for the number of elements. The boundary conditions applied to the model are the definition of the supports and the conditions of contact with the pin and the desired loading. For the two-edged head of the specimen, all degrees of freedom of points are applied, including displacement and rotation in all directions. For the single-page end of the model, the value of the failure of tensile impact obtained from the test conditions of the specimens, which was $526 \mathrm{~kJ} / \mathrm{m}^{2}$, is applied. Fig. 11 shows Boundary conditions for connections and Fig. 12 shows Contact conditions for connections.

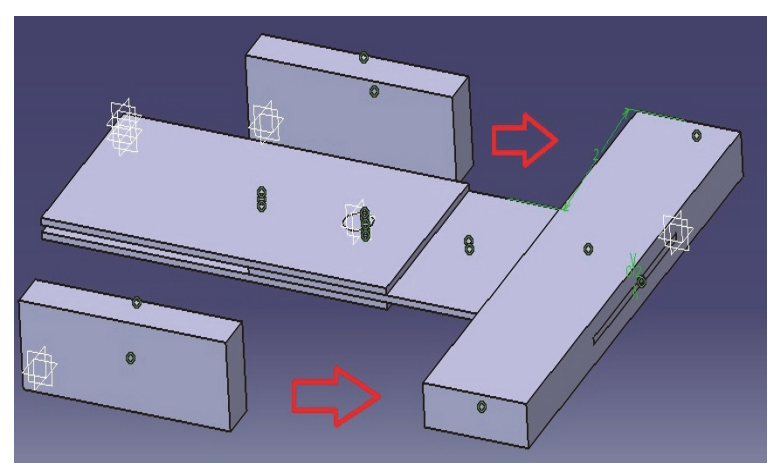

Figure 10: Specimen and jaw simulation in ABAQUS software.

In this problem, the contact between the components is considered and to obtain the Hashin failure criterion, the contact between the plates with a coefficient of friction of 0.2 and also the contact between the plates with the pin is defined so that the pin effect can be seen in the plates when applying force. The pin and all the pages were designed with the contact conditions of the Surface to surface, and the couplings of the layers were connected to each other by connecting Tie. 


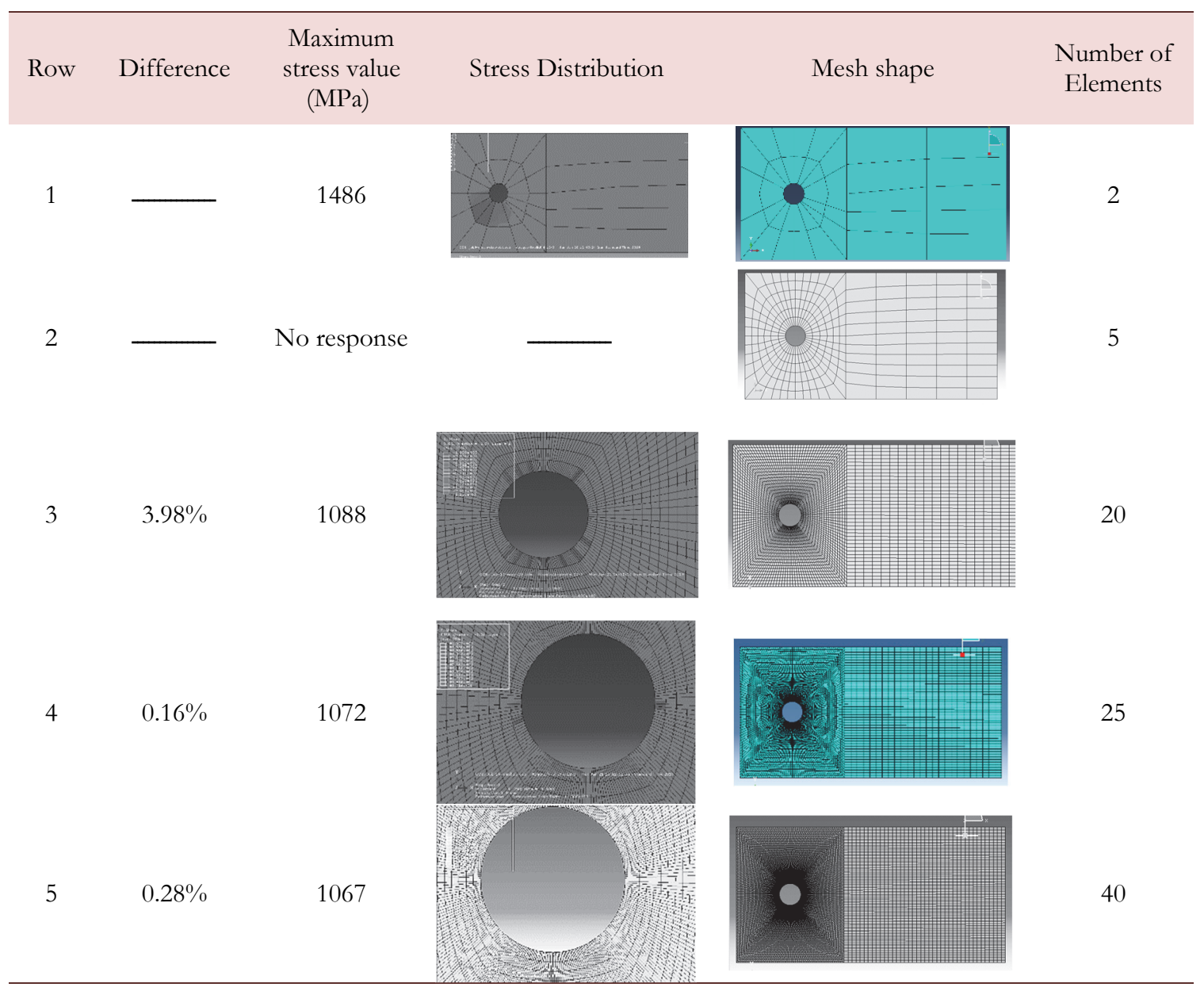

Table 6: The results of mesh convergence.

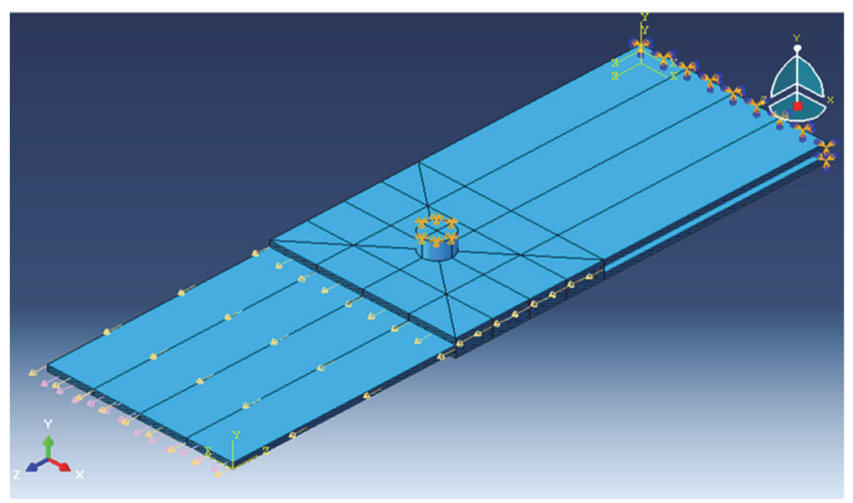

Figure 11: Boundary conditions for connections.

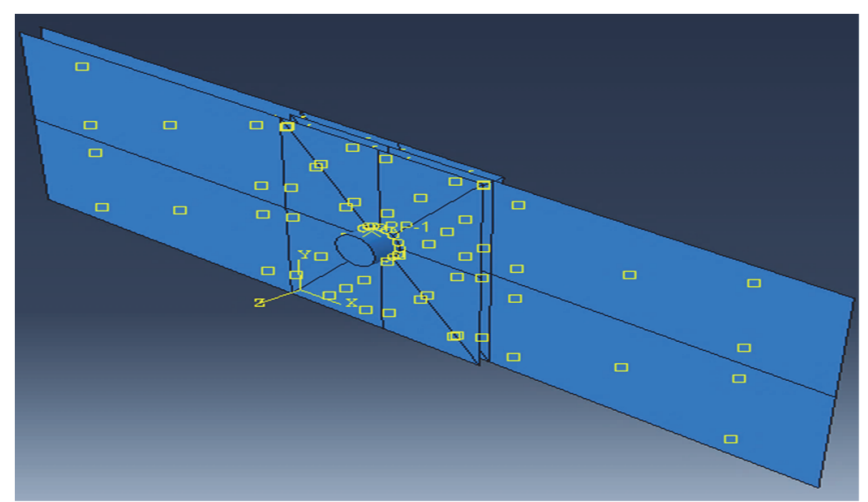

Figure 12: Contact conditions for connections.

\section{RESULTS AND DISCUSSION}

he time-diagram of the failure occurrence for the elements around the hole in the specimen can be seen according to the following formula based on the Hashian failure criterion: Fig. 13 Selection of round hole elements for strength diagram and Fig. 14 Diagram of failure criterion in time for round hole elements and Fig. 15 The direction of failure in the specimen under experimental test and Fig. 16 Direction of failure in modeling specimen is shown. 


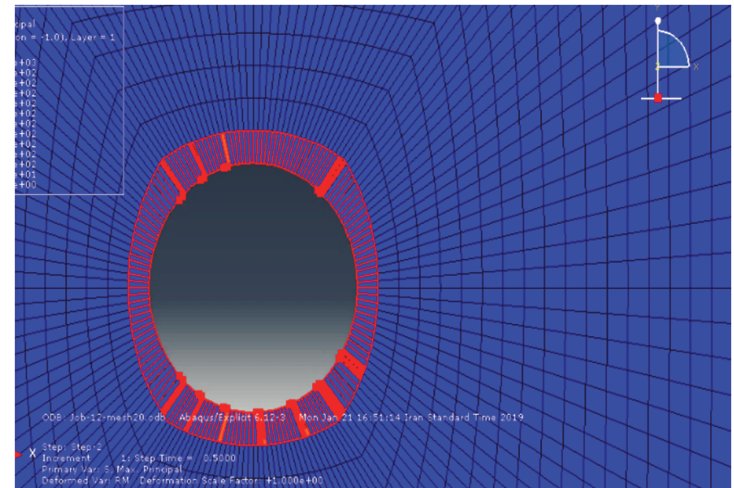

Figure 13: Selection of round hole elements for strength diagram.

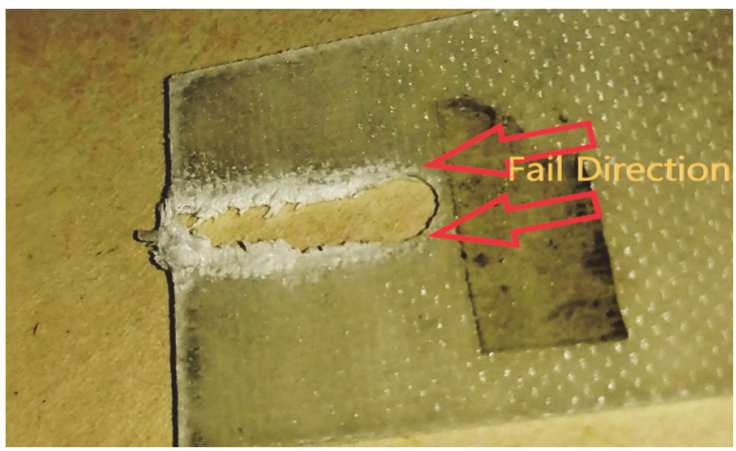

Figure 15: The direction of failure in the specimen under experimental test.

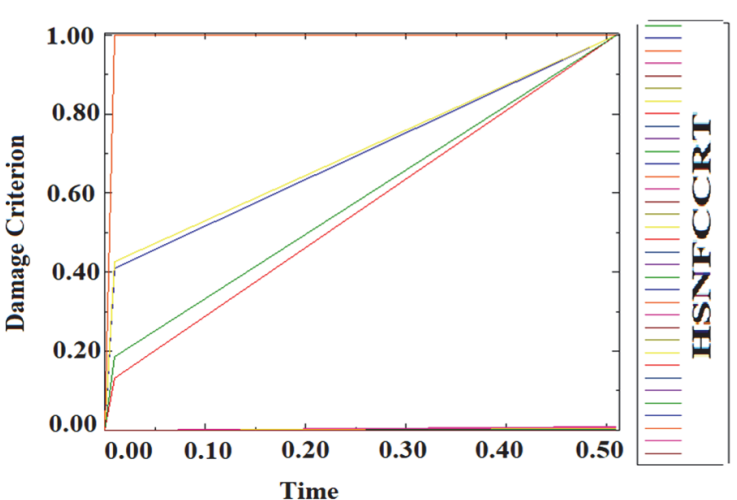

Figure 14: Diagram of failure criterion in time for round hole elements.

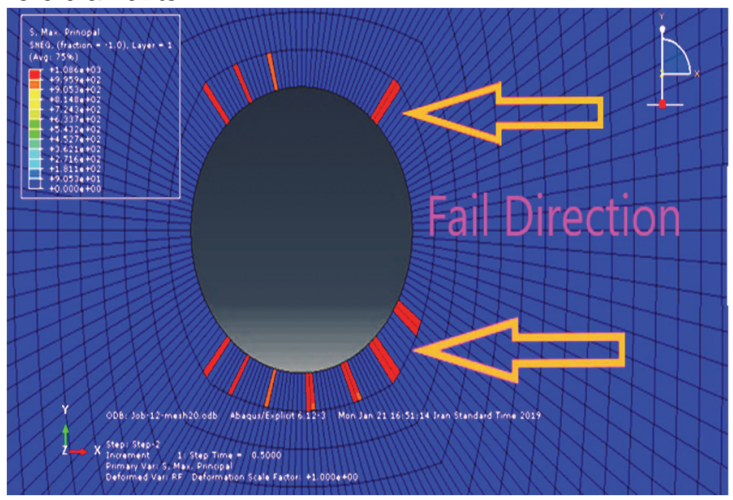

Figure 16: Direction of failure in modeling specimen.

After numerical simulation of the layer $\left[90^{\circ}, 0^{\circ},-45^{\circ}, 45^{\circ}\right] \mathrm{s}$ in Abacus software and applying all boundary and loading conditions, the experimental and numerical results can be seen in the following table:

\begin{tabular}{cccc}
\hline Number & Comparison index & Unit & Result \\
1 & $\begin{array}{c}\text { Fracture energy against tensile impact in } \\
\text { experimental testing }\end{array}$ & $\mathrm{kJ} / \mathrm{m}^{2}$ & 526 \\
2 & $\begin{array}{c}\text { Fracture energy against tensile impact in } \\
\text { numerical simulation }\end{array}$ & $\mathrm{kJ} / \mathrm{m}^{2}$ & 589 \\
& $\begin{array}{c}\text { The amount of difference } \\
\mathrm{kJ} / \mathrm{m}^{2}\end{array}$ & 63 \\
Percentage difference compared to numerical results & \multicolumn{2}{c}{$12 \%$} & \\
\hline
\end{tabular}

Table 7: Comparison of fracture energy of experimental and numerical results:

The difference between the experimental and numerical results is at an acceptable level of $12 \%$, which concludes that the simulated numerical model has good accuracy and can be a tool for future analysis used. The effect of different layers on the final strength of the structure is investigated. The most critical part of the model is the pin hole for the middle plate. Fig. 17 The angle of the fiber layer in the simulation model is shown.

To find the best effect of the layer, it is necessary to know the stress distribution along the thickness of the material, so first the problem is expressed at constant angles and two angles to study the behaviour of the material in the inter-layer angular changes then the layer Selects different materials on the material. Investigating the different layers, it was found that the stresses applied to the different layers are different, for example in the specimen with layer s $\left[0^{\circ}, 45^{\circ}, 90^{\circ},-45^{\circ}\right]$ This is showed in Fig. 18. 


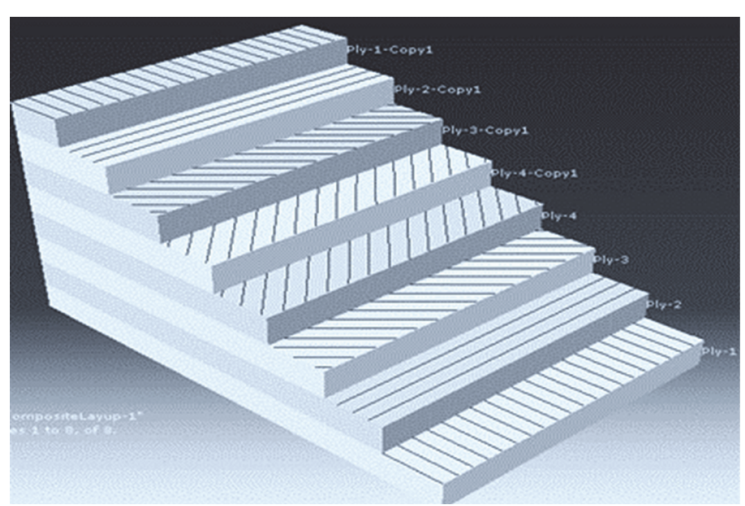

Figure 17: The angle of the fiber layer in the simulation model.

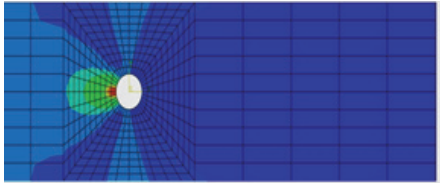

$0^{\circ}$

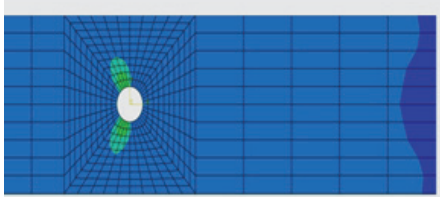

$-45^{\circ}$

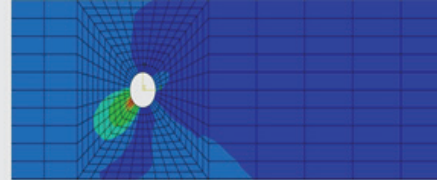

$45^{\circ}$

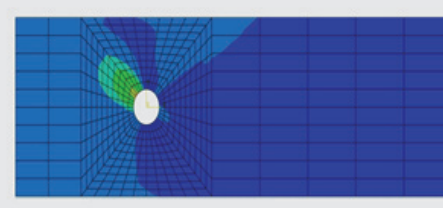

$90^{\circ}$

Figure 18: Stress distribution in different layers around the hole.

By layering $90^{\circ}$ for 8 layers of fibers in the desired model the stress distribution around the hole is reduced and the plate of one element which is the critical element of the model fails. This may be due to the fact that after the shock is applied, the plate enters the force at the edge of the hole at the edge of the plate, and the fibers at $90^{\circ}$ angle prevent the piece from failure, and just where the hole is at this angle. Approaching the front edge of the hole causes the fibers to failure at that point. As a result, in this case the plate may fail and with only $45^{\circ}$ angles observed, there is a high critical stress to the component around the pin hole, but the component is less stressed in the rest. Due to the symmetry of the model, the following layers are not considered as high or low as the top and bottom have another page. But in this model there is a pin hole and around the hole to prevent delamination and premature damage the fibers have to be perpendicular to the hole in a number of directions in order to spread the stress and prevent fracture. In Tab. 8, it is shown the comparison of fracture energy for different angles.

According to the table above the energy required to fracture the specimen across all layers varies with each other, with different angles being the best way to select the start of the layer with an angle of $0^{\circ}$, because this mode has the highest fracture energy. Then a $45^{\circ}$ angle then $90^{\circ}$ is best for reducing stress distribution and increasing fracture energy. Investigating the layer with the highest amount of energy absorption and in order to find the best one, changing the input variables and observing the different answers can be the best choice. By changing the possible layers and recording the results, we select the best layer. In this paper, Design Expert software is used to optimize it with response surface method (RSM), It is a collection of mathematical and statistical techniques to match the experimental data with polynomial models. RSM Method is presented as one of the experimental modeling methods. RSM Method is one of the approaches in the design of experiments and sciences. In the response surface method, the solution is to try to find a way to estimate the second - order effects and even the local form of the response surface. In this study, specific goals are pursued seriously, which can be used to improve the process by finding optimal inputs, removing the problems and weaknesses of the process and stabilizing it. Here, stabilization is an important concept in quality statistics which indicates minimizing the effects of secondary variables or friction [20]. Benefits of RSM method:

1) It analyzes the interaction between parameters.

2) quadratic models can be used to analyze properties and optimization.

3) in this method statistical method is determined by interpolation between input variables, optimal values.

4) (RSM)method can also receive qualitative variables and be used in analysis and optimization of properties. 
In Tab. 9, it is shown the analysis of variance (ANOVA) for different layers for the Design Expert software.

\begin{tabular}{cccccc}
\hline Row & L 1 Degree & L 2 Degree & L 3 Degree & L 4 Degree & Energy $(\mathrm{kJ})$ \\
1 & 0 & 45 & -45 & 90 & 633 \\
2 & 0 & 45 & 90 & -45 & 653 \\
3 & 0 & -45 & 45 & 90 & 633 \\
4 & 0 & -45 & 90 & 45 & 653 \\
5 & 0 & 90 & 45 & -45 & 589 \\
6 & 0 & 90 & -45 & 45 & 589 \\
7 & 45 & 0 & -45 & 90 & 626 \\
8 & 45 & 0 & 90 & -45 & 583 \\
9 & 45 & -45 & 0 & 90 & 565 \\
10 & 45 & -45 & 90 & 0 & 565 \\
11 & 45 & 90 & 0 & -45 & 582 \\
12 & 45 & 90 & -45 & 0 & 626 \\
13 & -45 & 0 & 45 & 90 & 627 \\
14 & -45 & 0 & 90 & 45 & 581 \\
15 & -45 & 45 & 0 & 90 & 564 \\
16 & -45 & 45 & 90 & 0 & 566 \\
17 & -45 & 90 & 0 & 45 & 584 \\
18 & -45 & 90 & 45 & 0 & 627 \\
19 & 90 & 0 & 45 & -45 & 547 \\
20 & 90 & 0 & -45 & 45 & 548 \\
21 & 90 & 45 & 0 & -45 & 608 \\
22 & 90 & 45 & -45 & 0 & 590 \\
23 & 90 & -45 & 0 & 45 & 607 \\
24 & 90 & -45 & 45 & 0 & 592 \\
25 & 0 & 45 & -45 & -90 & 633 \\
\hline & & & & & \\
\hline
\end{tabular}

Table 8: Comparison of fracture energy for different angles.

\begin{tabular}{cccccc}
\hline Std & Block & $\begin{array}{c}\text { Factor 1 } \\
\text { A: Layer 1 }\end{array}$ & $\begin{array}{c}\text { Factor 2 } \\
\text { B: Layer 2 }\end{array}$ & $\begin{array}{c}\text { Factor 3 } \\
\text { C: Layer 3 }\end{array}$ & $\begin{array}{c}\text { Factor 4 } \\
\text { D: Layer 4 }\end{array}$ \\
1 & Block 1 & 0.00 & 45.00 & -45.00 & 90.00 \\
2 & Block 1 & 0.00 & 45.00 & 90.00 & -45.00 \\
3 & Block 1 & 0.00 & -45.00 & 45.00 & 90.00 \\
4 & Block 1 & 0.00 & -45.00 & 90.00 & 45.00 \\
5 & Block 1 & 0.00 & 90.00 & 45.00 & -45.00 \\
6 & Block 1 & 0.00 & 90.00 & -45.00 & 45.00 \\
7 & Block 1 & 45.00 & 0.00 & -45.00 & 90.00 \\
8 & Block 1 & 45.00 & 0.00 & 90.00 & -45.00 \\
9 & Block 1 & 45.00 & -45.00 & 0.00 & 90.00 \\
10 & Block 1 & 45.00 & -45.00 & 90.00 & 0.00 \\
11 & Block 1 & 45.00 & 90.00 & 0.00 & -45.00 \\
12 & Block 1 & 45.00 & 90.00 & -45.00 & 0.00 \\
13 & Block 1 & -45.00 & 0.00 & 45.00 & 90.00 \\
14 & Block 1 & -45.00 & 0.00 & 90.00 & 45.00 \\
15 & Block 1 & -45.00 & 45.00 & 0.00 & 90.00 \\
16 & Block 1 & -45.00 & 45.00 & 90.00 & 0.00 \\
17 & Block 1 & -45.00 & 90.00 & 0.00 & 45.00 \\
18 & Block 1 & -45.00 & 90.00 & 45.00 & 0.00 \\
19 & Block 1 & 90.00 & 0.00 & 45.00 & -45.00 \\
20 & Block 1 & 90.00 & 0.00 & -45.00 & 45.00 \\
21 & Block 1 & 90.00 & 45.00 & 0.00 & -45.00 \\
22 & Block 1 & 90.00 & 45.00 & -45.00 & 0.00 \\
23 & Block 1 & 90.00 & -45.00 & 0.00 & 45.00 \\
24 & Block 1 & 90.00 & -45.00 & 45.00 & 0.00 \\
25 & Block 1 & 0.00 & 45.00 & -45.00 & -90.00 \\
\hline
\end{tabular}

Table 9: Analysis of variance (ANOVA)for different layers. 
Optimization of dispersion parameters for the layers for maximum fracture energy, Fig. 19, and Fig. 20, Three-dimensional optimization results is shown.
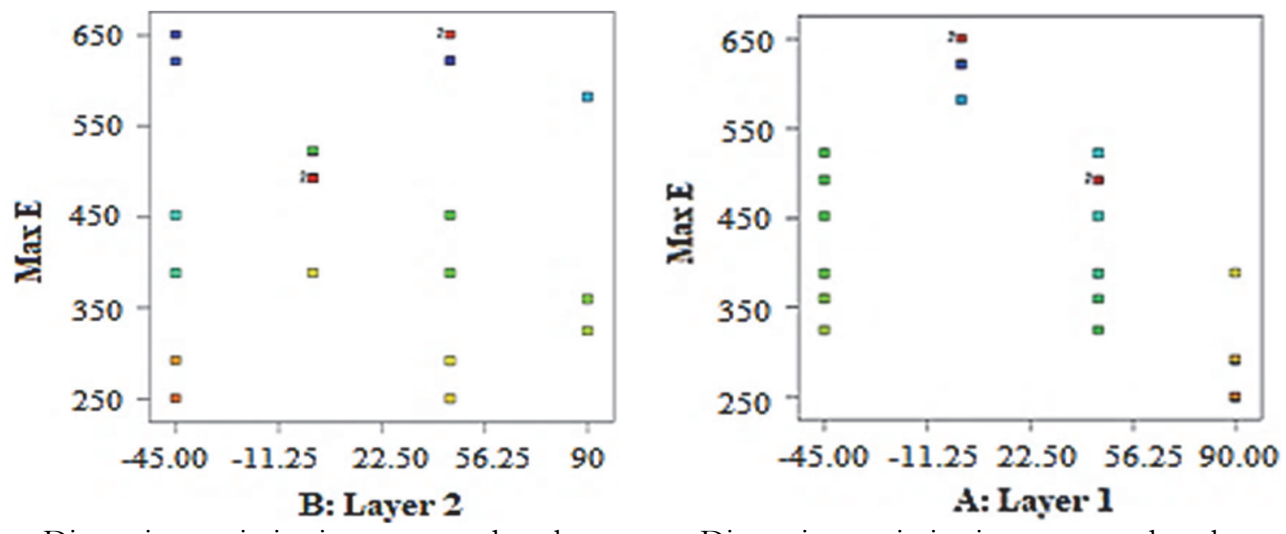

Dispersion optimization compared to the

Dispersion optimization compared to the

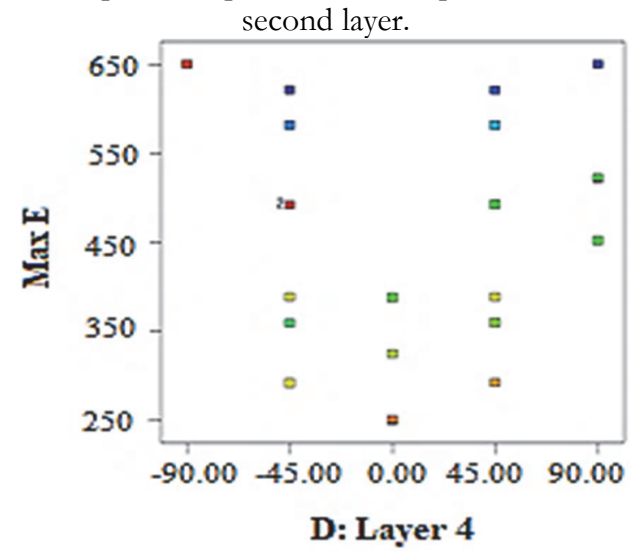

Dispersion optimization compared to the fourth layer.

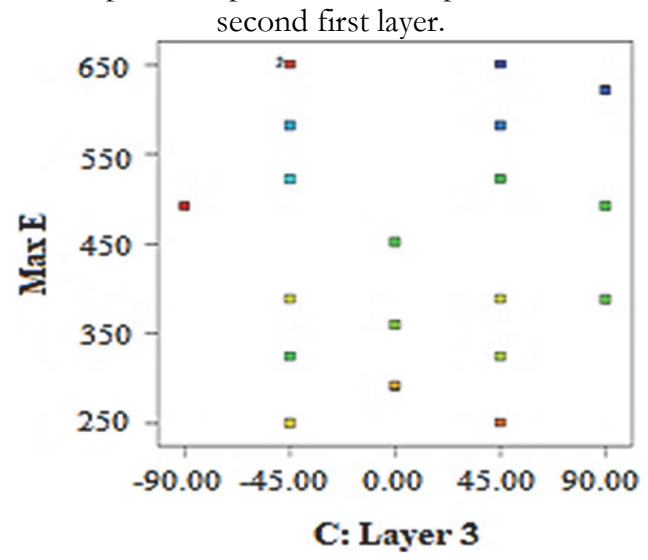

Dispersion optimization compared to the third layer.

Figure 19: Optimization of dispersion parameters for the layers.

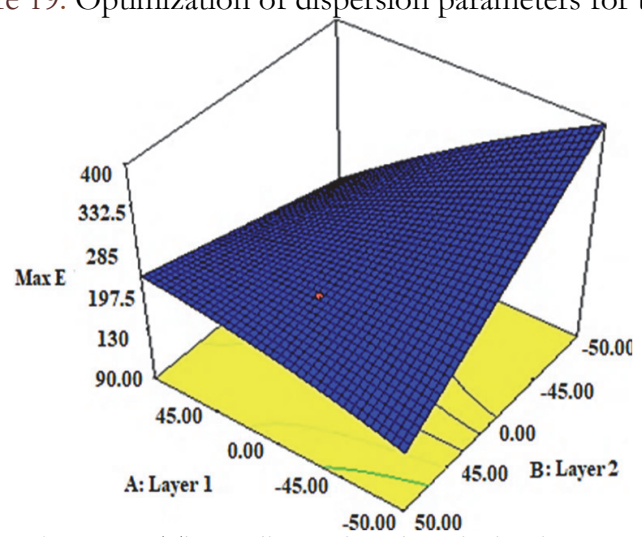

Figure 20: Three-dimensional optimization results.

According to the graph, the model with the highest fracture energy is given input settings where the first layer is $0^{\circ}$ and the second layer is $45^{\circ}$. As a result, the best layer is selected by the software as in Tab. 10:

\begin{tabular}{cccccc}
\hline Number & Layer 1 & Layer 2 & Layer 3 & Layer 4 & Max Desirability \\
1 & 0.00 & 45.00 & 90.00 & -45.00 & 1.000 \\
2 & 0.00 & -45.00 & 45.00 & 90.00 & 1.000 \\
\hline
\end{tabular}

Table 10: The Best layer evaluation by RSM Method. 


\section{CONCLUSIONS}

$\mathrm{B}$ y comparing the above results with those of previous researchers, a good agreement is observed in the results. Important results obtained from different layers:

1) By comparing the results obtained from numerical simulation and experimental test, it was observed that the fracture energy was 589 and $526 \mathrm{~kJ} / \mathrm{m}^{2}$ in the two states, respectively, and with an acceptable difference of $12 \%$, good agreement between the numerical and experimental results was observed.

2) The most critical area in the stress concentration obtained at the mechanical joint is around the piece hole.

3) The layers of $45^{\circ}$ fibers in the model is very important because these fibers play a significant role in increasing the shear strength under shear stresses due to the crossing of the stress flow lines along the holes; The maximum shear occurs at an angle of $45^{\circ}$ and these layers resist this shear stress.

4) Under constant loading, changing the rows of layers causes a change in the stress intensity at the desired joint.

5) The best way to choose from different angles is to start the layer with a $0^{\circ}$ angle, because by selecting this mode the least stress is applied to the piece.

6) In order to balance the stresses applied to each layer with respect to its strength, it is best to place the angles of $0^{\circ}$ and $90^{\circ}$ at angles of $\left[45^{\circ}\right.$ and $-45^{\circ}$ for better stress transfer.

7) The highest stress to the desired connection is related to the start of layering at a $90^{\circ}$ angle.

8) The layer can be designed in the order of $s\left[0^{\circ}, 45^{\circ}, 90^{\circ},-45^{\circ}\right]$ to achieve maximum strength.

\section{ACKNOWLEDGEMENTS}

$\mathrm{W}$

e thank the AmirKabir University Laboratory and Dana Plastic Test Company for conducting a research test.

\section{REFERENCES}

[1] Joshi, Satish V., Drzal, L. T., Mohanty, A. K. and Arora, S. (2004). Are natural fiber composites environmentally superior to glass fiber reinforced composites?. Composites Part A: Applied science and manufacturing 35(3), pp. 371-376.

DOI: 10.1016/j.compositesa.2003.09.016.

[2] Liu, Y., Du, H., Liu, L. and Leng, J. (2014). Shape memory polymers and their composites in aerospace applications: a review, Smart Materials and Structures, 23(2), p. 023001.

https://iopscience.iop.org/article/10.1088/0964-1726/23/2/023001/meta

[3] Long, S., Yao, X. and Zhang, X. (2015). Delamination prediction in composite laminates under low-velocity impact, Composite Structures, 132, pp. 290-298. DOI: 10.1016/j.compstruct.2015.05.037

[4] Singh, M., Bhunia, H. and Saini, J. (2015). Effect of ply orientation on strength and failure mode of pin jointed unidirectional glass-epoxy nanoclay laminates, Defence Science Journal, 65(6), pp. 489-499. DOI: 10.14429/dsj.65.8917

[5] Senthilkumar, K., Siva, I., Jappes, J. W., Amico, S. C., Cardona, F., and Sultan, M. (2016). Effect of inter-laminar fibre orientation on the tensile properties of sisal fibre reinforced polyester composites, in IOP Conference Series: Materials Science and Engineering, 152(1), p. 012055. https://iopscience.iop.org/article/10.1088/1757-899X/152/1/012055/meta

[6] Jogi, S. A., Baloch, M. M., Chandio, A., Memon, I. A., and Chandio, G. S. (2017). Evaluation of Impact Strength of Epoxy Based Hybrid Composites Reinforced with E-Glass/Kevlar 49, Mehran University Research Journal of Engineering and Technology, 36(4), pp. 1009-1016. https://hal.archives-ouvertes.fr/hal-01705594

[7] Binnur Goren, K. (2010). Effect of the Clearance and Interference-fit on Failure of the Pin-Loaded Composites, Materials and Design (2010) 31, pp. 85-93. DOI: 10.1016/j.matdes.2009.07.009

[8] Mishra, A., Naik, N. K. (2010). Failure initition in composite structures under low-velocity impact: Analytical studies. Composite Structures,92, pp. 436-444. DOI: 10.1016/j.compstruct.2009.08.024

[9] Kapti, S., Sayman, O., Ozen, M., Benli, S. (2010). Experimental and Numerical Failure Analysis of Carbon/Epoxy Laminated Composite Joints under Different Conditions, Materials and Design, 31, pp. 4933-4942. 
DOI: $10.1016 /$ j.matdes.2010.05.018

[10] Hasan's, M., Naderi, A.R., Bushroa, (2014). Low-velocity impact damage of woven fabric composite: Finite element Simulation and experimental verification Materials and Design, 53, pp. 706-718. DOI: 10.1016/j.matdes.2013.07.068

[11] Liang, W., Zhiwei, D., Zhenqing, W. and Pengcheng, L. (2015). Experimental and numerical investigation on bolted joint in glass-fiber reinforced composites., Advanced Composite Materials 24(1), pp.161-173. DOI: $10.1080 / 09243046.2014 .976733$

[12] Machado, J. J. M., Gamarra, P. R., Marques, E. A. S., da Silva, L. F. (2018). Numerical study of the behaviour of composite mixed adhesive joints under impact strength for the automotive industry. Composite Structures, 185, pp. 373-380. DOI: 10.1016/j.compstruct.2017.11.045

[13] Liu, B., Han, Q., Zhong, X., and Lu, Z. (2019). The impact damage and residual load capacity of composite stepped bonding repairs and joints. Composites Part B: Engineering, 158, 339-351. DOI: 10.1016/j.compositesb.2018.09.096.

[14] Ondurucu, U., Esendemir and Tunay, R.F. (2012). Progressive failure analysis of glass-epoxy laminated composite pinned-joints, Material and Design, 36, pp. 617-625. DOI: 10.1016/j.matdes.2011.11.031.

[15] Najafi, S. K. (2013). Use of recycled plastics in wood plastic composites-A review. Waste management 33(9) pp. 18981905. DOI: $10.1016 /$ j.wasman.2013.05.017.

[16] Chamis, C.C., (1969). Failure Criteria for Filamentary Composites, Composite Materials: Testing and Design, STP 460, ASTM, Philadelphia: pp. 336-351. DOI: 10.1520/STP49826S.

[17] Taghipoor, H., and Damghani Noori, M. (2018). Experimental and numerical study on energy absorption of latticecore sandwich beam. Steel and Composite Structures, 27(2), pp. 135-147. DOI: 10.12989/scs.2018.27.2.135.

[18] Harhash, M., Rose Rogin, G., Hartmann, S. and Palkowski, H. (2020). Experimental characterization, analytical and numerical investigations of metal/polymer/metal sandwich composites-Part 2: Free bending. Composite Structures 232, pp. 111421. DOI: 10.1016/j.compstruct.2019.111421

[19] Aghaei-Ruzbahani, M., Shahgholian-Ghahfarokhi, D. and Rahimi, Gh (2020). Experimental Analysis of Composite Sandwich Plates Buckling with Lozenge Core Using the Vibration Correlation Technique. Modares Mechanical Engineering, 20(5), pp. 1399-1408. https://mme.modares.ac.ir/browse.php?a_id=33320\&sid=15\&slc_lang=en

[20] Moslemi Petrudi, A., Fathi, P. and Rahmani, M. (2020). Multi-objective Optimization to Increase Nusselt Number and Reduce Friction Coefficient of Water/Carbon Nanotubes via NSGA II using Response Surface Methodology, J. Mod. Sim. Mater., 3(1), pp. 1-14. .

[21] Li, D., Peng, X., Zhenyu, H. and Quanqi, Z. (2020). Mechanical and failure properties of rocks with a cavity under coupled static and dynamic loads. Engineering Fracture Mechanics 225, pp. 106195.

DOI: 10.1016/j.engfracmech.2018.10.021

[22] Yuan, C., Wensu, C., Thong, M., Pham, Hong, H., Jian, C., and Yanchao, S. (2020). Interfacial bond behaviour between hybrid carbon/basalt fibre composites and concrete under dynamic loading. International Journal of Adhesion and Adhesives, 99, p.102569. DOI: 10.1016/j.ijadhadh.2020.102569

[23] Li, X., Yu, W., Chenglin, C., Linyuan, H., Jing, B. and Feng, X. (2020). A study on Mg wires/poly-lactic acid composite degradation under dynamic compression and bending load for implant applications. Journal of the Mechanical Behavior of Biomedical Materials, 105, pp. 103707. DOI: 10.1016/j.jmbbm.2020.103707 